\title{
Human skin bacterial flora differ with altitudes in different ethnic groups of Nepal
}

\author{
Dipendra Shrestha', Raju Shrestha ${ }^{2}$, Rene S. Hendriksen ${ }^{3}$, Luna Bhatta Sharma ${ }^{4}$ and \\ Dwij Raj Bhatta ${ }^{5}$ \\ ${ }^{1} \mathrm{PhD}$ Scholar, Central Department of Microbiology, Tribhuvan University, Kritipur, Kathmandu, Nepal, ${ }^{2}$ Quality Controller \\ Officer, Deurali-Janata Pharmaceuticals P. Ltd., Kathmandu, Nepal, ${ }^{3}$ Senior Scientist, National Food Institute, Technical \\ University of Denmark, Kemitorvet, Denmark, ${ }^{4}$ Visiting Faculty (Microbiology), Saint Xavier's College, Tribhuvan \\ University, Maitighar, Kathmandu, ${ }^{5}$ Professor, Central Department of Microbiology, Tribhuvan University, Kritipur, \\ Kathmandu, Nepal
}

Background: Largest organ of human body, the skin, is colonized by millions of microorganisms, most of which are not only harmless but also beneficial to the host. Human skin microbes depend upon geographical variations, ethnicity and various host factors. Despite several studies on human skin microbiota in various parts of the globe, it has not been studied in Nepalese population. Aims and Objective: To identify skin bacterial normal flora in different ethnic groups residing in different altitude of Nepal. Materials and Methods: We cultured skin swabs of 166 randomly selected volunteers belonging to 10 major ethnic groups from 3 distinct geographical altitudes of Nepal, viz. Bharatpur (415 m from sea level), Kathmandu $(1,400 \mathrm{~m}$ from sea level) and Lukla $(2,860 \mathrm{~m}$ from sea level). The isolated organisms were characterized and tested for their susceptibility against different antibiotics. Results: Altogether 231 bacterial isolates were characterized from 166 skin samples. Among them, 140 isolates (60.60 \%) were Gram positive and 91 isolates (39.40\%) were Gram negative bacteria. Staphylococcus aureus (35.49\%) was the most dominant skin bacterial flora followed by Escherichia coli (22.51\%) and Streptococcus spp. (17.75\%). Medium altitude Kathmandu exhibited the highest growth (120 isolates) followed by low land Bharatpur (66 isolates) and high land Lukla (51 isolates) which is statistically significant ( $p$ value $=0.0124$ ). The antibiotic susceptibility testing against 14 antibiotics exhibited the Gram positive isolates were the most sensitive to Imipenem (94.93\%) whereas the least sensitive to Cephalexin $(31.36 \%)$ and the Gram negative isolates were the most sensitive to Amikacin $(100 \%)$ whereas the least sensitive to Amoxycillin (28.57\%). Conclusion: Our data indicates that the skin bacterial normal flora; which is directly exposed to external environment; has significant relationship with altitudes where individuals live. The result desires further study for the adaptability of normal flora found in different altitudes. Some bacterial commensals were found resistant even against new generations of antibiotics as well, and hence can cause life-threatening infections if they happen to cross the skin physical barrier.

Key words: Normal flora; Ethnicity; Altitudes

\section{INTRODUCTION}

Skin is a diverse ecosystem extending about $1.8 \mathrm{~m}^{2}$ surface area in adult human. In general, skin is cool, acidic and desiccated. Skin primarily contributes as physical barrier, protecting sensitive organs from foreign organisms, toxic elements and physical injury while retaining nutrients. ${ }^{1}$ Skin supports the growth of commensal bacteria, which, in turn, protects skin from pathogenic bacteria..$^{2-4}$

Human skin microbiota also produces modulators of immune system, such as short-chain fatty acids and 
metabolites of tyrosine or tryptophan; up regulates regulatory $\mathrm{T}$ lymphocytes, ${ }^{5}$ and produces bacteriocin to out compete skin pathogens. ${ }^{6}$

Human skin bacterial communities appear to be diverse. The diversity is obscure owing to the complexity of the physiology of the skin. ${ }^{7}$ Skin exhibits distinct and diverse habitats for normal flora depending upon skin thickness, invaginations, folds and density of hair follicles and glands. ${ }^{1,8}$ Skin microbial diversity is also influenced by the environment, as well as host sex, species, behavioral factors and genetics. ${ }^{9-11}$

Physiological and anatomical differences between male and female cutaneous environments such as sweat, sebum and hormone production, partially account for the microbial differences seen among the genders.?

Intrapersonal variation in microbial community membership and structure between symmetric skin sites is lesser than the interpersonal variation. ${ }^{12}$

Skin is the interface between the human and environment. The skin of the human living in high altitude is exposed to various extreme conditions such as hypobaric pressure, hypoxia, high ultraviolet radiation; and cold and dry environment. ${ }^{13}$ These conditions exert a substantial selective pressure on skin microbiome and hence the skin microbiomes differ with altitude in terms of diversity and number. ${ }^{14}$

This study aims to isolate and identify the skin bacterial flora from 10 different ethnic groups residing in 3 distinct altitudes of Nepal; ranging from low land Terai region to high mountains. It will help to trace the microbial diversity in them.

\section{MATERIALS AND METHODS}

\section{Study subject}

One hundred and sixty-six healthy volunteers, 80 males and 86 females, of 10 ethnic groups, age 18-25 as inclusion criteria, with no history of dermatologic disorders (mild acne or other common features other than forehead acceptable) or other chronic medical disorders and with no current skin infections and antibiotic therapy were selected for our study. The ethnic groups under study are among major ethnic groups of Nepal; Brahmin ( $\mathrm{n}=32)$, Chhetri $(\mathrm{n}=30)$, Newar ( $\mathrm{n}=21)$, Tamang $(\mathrm{n}=17)$, Chaudhary $(\mathrm{n}=14)$, Gurung $(\mathrm{n}=12)$, Magar $(\mathrm{n}=10)$, Dalit $(\mathrm{n}=10)$, Kirat $(n=11)$ and Sherpa $(n=9)$. The volunteers were asked to fill up form to interrogate their behavioral and physiological information. Written consented was taken from the volunteers for sample collection and data publication prior to sample collection. Ethical approval was received from Nepal Health Research Council (Regd no. 311/2018).

\section{Geographical regions}

The sample sites were Bharatpur, Kathmandu and Lukla of Nepal as indicated in the map 1.

Kathmandu, the capital city of Nepal, is the medium altitude site located $1400 \mathrm{~m}$ (4600 feet) above sea level. The GPS coordinate is $27.7172^{\circ} \mathrm{N}$ and $85.7172^{\circ} \mathrm{E}$.

Bharatpur is a low altitude city in Chitwan district of Nepal, only $208 \mathrm{~m}$ (682 feet) above sea level. It is situated in the mid-southern part of Nepal, $87 \mathrm{~km}$ southwards from Capital city, Kathmandu. The GPS coordinate for Bharatpur is $27.6847^{\circ} \mathrm{N}$ and $84.4173^{\circ} \mathrm{E}$.

Lukla is a high altitude village in Solukhumbu district, the gateway to the highest peak of the world, Mount Everest. It

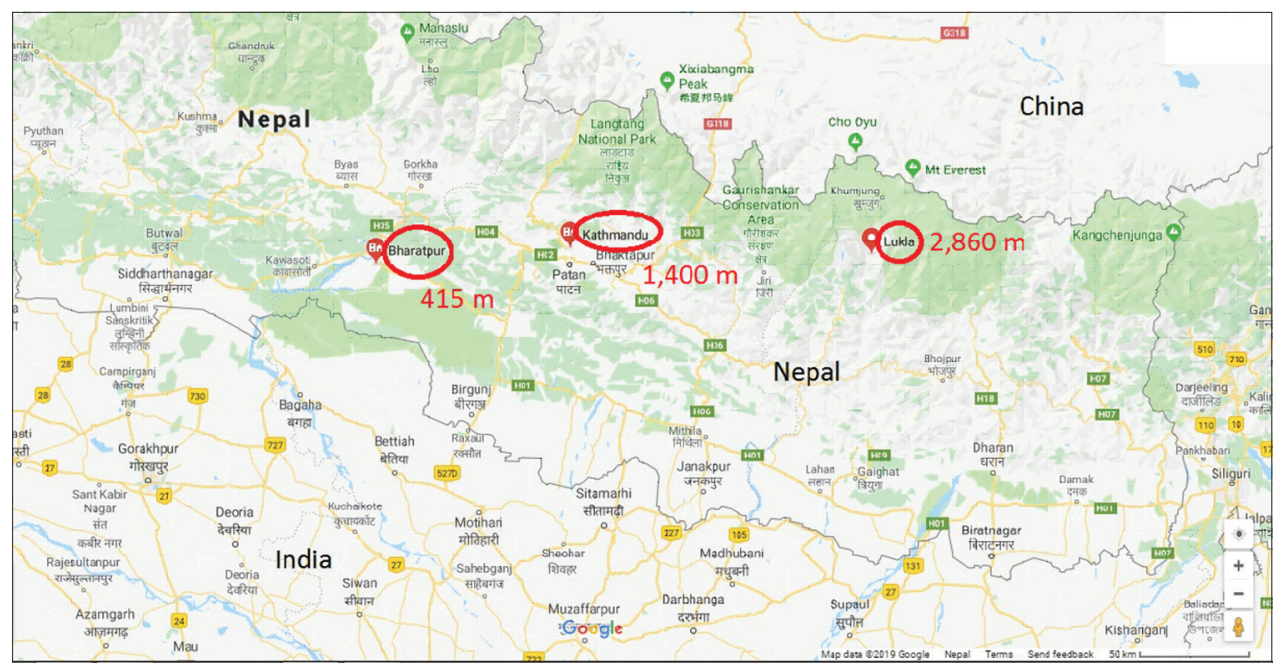

Map 1: Map showing sampling sites as indicated with Red circle 


\begin{tabular}{|c|c|c|c|c|c|c|c|c|c|}
\hline \multirow[t]{2}{*}{ S. No. } & \multirow[t]{2}{*}{ Organism } & \multicolumn{2}{|c|}{ Bharatpur $(n=60)$} & \multicolumn{2}{|c|}{ Kathmandu $(n=55)$} & \multicolumn{2}{|c|}{ Lukla $(n=51)$} & \multicolumn{2}{|c|}{ Total $(n=166)$} \\
\hline & & $n$ & $\%$ & $n$ & $\%$ & $n$ & $\%$ & $n$ & $\%$ \\
\hline 1 & Staphylococcus aureus & 16 & 26.66 & 33 & 60 & 33 & 64.70 & 82 & 35.49 \\
\hline 2 & Escherichia coli & 30 & 50 & 22 & 40 & 0 & 0 & 52 & 22.51 \\
\hline 3 & Streptococcus spp & 7 & 11.66 & 27 & 49.09 & 7 & 13.72 & 41 & 17.75 \\
\hline 4 & Klebsiella oxytoca & 2 & 3.33 & 10 & 18.18 & 0 & 0 & 12 & 5.19 \\
\hline 5 & Micrococcus luteus & 0 & 0 & 8 & 14.545 & 1 & 1.96 & 9 & 3.89 \\
\hline 6 & Neisseria spp & 0 & 0 & 3 & 5.45 & 2 & 3.92 & 5 & 2.16 \\
\hline 7 & Acinetobacter baumannii & 5 & 8.33 & 0 & 0 & 0 & 0 & 5 & 2.16 \\
\hline 8 & Bacillus subtilis & 0 & 0 & 5 & 9.09 & 0 & 0 & 5 & 2.16 \\
\hline 9 & Citrobacter freundii & 1 & 1.66 & 4 & 7.27 & 0 & 0 & 5 & 2.16 \\
\hline 10 & Enterobacter aerogenes & 0 & 0 & 5 & 9.09 & 0 & 0 & 5 & 2.16 \\
\hline 11 & Proteus mirabilis & 4 & 6.66 & 1 & 1.81 & 0 & 0 & 5 & 2.16 \\
\hline 12 & Staphylococcus epidermidis & 1 & 1.66 & 0 & 0 & 2 & 3.92 & 3 & 1.20 \\
\hline \multirow[t]{2}{*}{13} & Pseudomonas aeruginosa & 0 & 0 & 2 & 3.63 & 0 & 0 & 2 & 1.20 \\
\hline & Total isolates & 66 & & 120 & & 45 & & 231 & \\
\hline
\end{tabular}

is $2860 \mathrm{~m}$ (9380 feet) from sea level. The GPS coordinates for Lukla is $27.6857^{\circ} \mathrm{N}$ and $86.7278^{\circ} \mathrm{E}$. It is $138 \mathrm{~km}$ East from Kathmandu.

\section{Sample collection}

Subjects were instructed not to wash face with anything, including water alone, for a 4 hour interval prior to sampling, but otherwise were allowed using not wet materials, for example handkerchief. Informed consents were obtained from all participants. All procedure done in aseptic way. Sterile cotton swab, soaked in sterile $0.9 \%$ sodium chloride with $0.1 \%$ Tween-20 solution, was vigorously rubbed in $2 \mathrm{~cm} \mathrm{X} 2 \mathrm{~cm}$ area of the middle forehead for around 1 minute. ${ }^{15}$

Skin swab samples were collected from human samples of Kathmandu $(\mathrm{n}=55)$, Bharatpur $(\mathrm{n}=60)$ and Lukla $(\mathrm{n}=51)$ and processed in Kantipur General Hospital Laboratory, Kathmandu; Balkumari College Microbiology Laboratory, Chitwan and Pasang Lhamu Memorial Hospital Laboratory, Lukla respectively.

\section{Sample processing}

Skin swabs were inoculated in Nutrient, MacConkey, Blood and Chocolate Agar culture plates and incubated at $37^{\circ} \mathrm{C}$ for 24 hours. Colonies were observed, noted and sub cultured for obtaining pure culture. The isolates were identified by using microbiological tools and techniques as described in the Bergey's manual of systematic bacteriology which involves morphological appearance of the colonies, staining reaction and biochemical properties. Each of the organisms was isolated in pure form before performing biochemical and other tests. The biochemical tests used for the identification include Catalase test, Oxidase test, Sulfide Indole and Motility (SIM) test, Methyl red test, Voges Proskauer test, Citrate utilization test, Oxidation Fermentation test, Triple Sugar Iron (TSI) test and Nitrate reduction test. ${ }^{16-17}$

\section{Antibiotic susceptibility testing}

The antimicrobial susceptibility testing of the isolates towards various antimicrobial disks was done by modified Kirby-Bauer disk diffusion method using Mueller Hinton agar (MHA). Pure culture colony was grown into Mueller Hinton broth tube at $37^{\circ} \mathrm{C}$ for $2-4$ hours until the turbidity of the suspension was matched with the turbidity standard of McFarland tube number 0.5. The bacterial suspension was inoculated into MHA using carpet culture technique and antibiotic discs were place over the carpet culture in aseptic way. The antibiotic discs used against Gram positive organisms were Amoxycillin, Cephalexin, Cefotoxin, Cefixime, Cefotaxime, Ceftriaxone, Cotrimoxazole, Ertythromycin, Gentamycin, Ciprofloxacin, Ofloxacin, Norfloxacin, Cloxacillin and Imipenem; and for Gram negative organisms were Amoxycillin, Cefixime, Cefotaxime, Ceftriaxone, Ceftazadime, Co-trimoxazole, Nitrofurantoin, Chloramphenicol, Amikacin, Gentamycin, Ciprofloxacin, Norfloxacin, Ofloxacin and Imipenem. The plates were left covered for few minutes after incorporating antibiotic discs which was then incubated at $37^{\circ} \mathrm{C}$ for 24 hrs. The plates were observed for zone of inhibition around antibiotic discs and measured in millimeter to compare with standardized zone interpretative chart provided by the company.

\section{Data analysis}

Data was entered and analysed using the Statistical Package for Social Sciences (SPSS), v23.0 (IBM SPSS Statistics, Armonk, NY). Descriptive statistics were applied to find frequencies, percentages and means. Qualitative variables, such as type of bacteria and antibiotics were expressed as frequencies and percentages. Chi-square tests were applied to compare the percentages of two categorical variables. Level of significance was set at $\mathrm{p}<0.05$. 


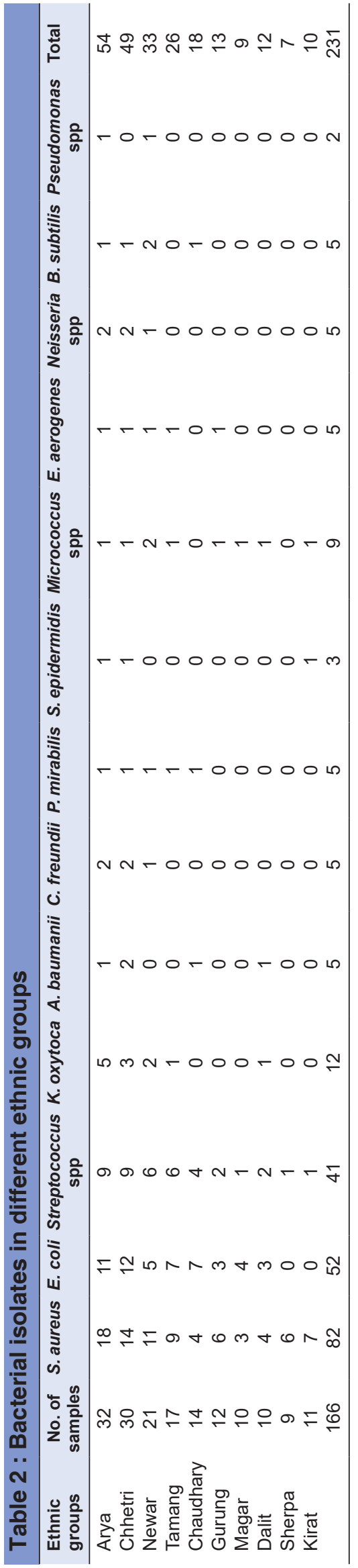

\section{RESULTS}

\section{Microbial diversity on different altitudes}

The most predominant skin aerobic bacterial flora was found to be Staphylococcus aureus isolated from $49.9 \%$ samples, followed by Escherichia coli and Streptococcus spp isolated from $31.32 \%$ and $24.69 \%$ samples respectively as shown in Table 1.

Skin swab samples from Kathmandu and Lukla exhibited Staphylococcus aureus as the most predominant skin flora from $60 \%$ and $64.70 \%$ samples respectively whereas that from Bharatpur exhibited E. coli as the most predominant skin flora growing in 50\% samples.

Kathmandu samples $(n=55)$ grew 120 isolates followed by 66 isolates observed from Bharatpur samples $(n=60)$. The least number of isolates were observed from Lukla samples $(n=51)$ that grew only 45 isolates. This relationship of total bacterial isolates from different altitudes of Nepal was found to be statistically significant $(\mathrm{p}$ value $=0.0124$ ).

Regarding the diversity of bacterial normal flora, skin samples from Kathmandu ( $\mathrm{n}=55)$ exhibited 10 bacterial genus, the highest among three altitudes. Bharatpur $(\mathrm{n}=60)$ and Lukla ( $\mathrm{n}=51)$ skin samples grew 7 and 4 genus of skin bacterial flora respectively. The relationship is, however, statically insignificant $(\mathrm{p}$ value $=0.8868)$.

\section{Microbial diversity on different ethnic groups}

Out of 10 ethnic groups, 8 ethnic groups exhibited S. aureus as the most predominant bacterial flora and 2 ethnic groups exhibited E. coli as the most predominant one as shown in Table 2. The relationship between the numbers of isolates with the ethnic groups, however, is found to be non-significant with p-value 0.9991 .

\section{Gender wise distribution of skin microbiome}

The bacterial flora isolated in skin of male was found slightly higher in ratio than that of female. 80 male samples exhibited 115 isolates and 86 female samples exhibited 116 isolates. The data observed, however, was statistically insignificant $(\mathrm{p}$ value $=0.9913) . S$. aureus was the most predominant isolates in both of the cases as shown in Table 3.

The number of isolates on the basis of altitude, however, was significant for both male and female samples separately with p-values 0.1632 and 0.2401 respectively. Kathmandu samples exhibited the highest number of isolates followed by Bharatpur and Lukla samples in both genders.

\section{Coorelation of human skin microbiota with selected} habits

The diversity of skin microbiome was found to be slightly higher in Non-alcoholic people with respect to Alcoholic. 


\begin{tabular}{llccc}
\multicolumn{4}{l}{$\begin{array}{l}\text { Table 3: Skin Normal flora distribution on sex } \\
\text { basis }\end{array}$} & \multicolumn{4}{l}{} \\
\hline S. No. & Skin Microbiome & $\begin{array}{c}\text { Male } \\
(\boldsymbol{n}=\mathbf{8 0})\end{array}$ & $\begin{array}{c}\text { Female } \\
(\boldsymbol{n}=\mathbf{8 6})\end{array}$ & Total \\
\hline 1 & S. aureus & 38 & 44 & 82 \\
2 & Streptococcus spp & 20 & 21 & 41 \\
3 & Micrococcus luteus & 4 & 5 & 9 \\
4 & Bacillus spp & 4 & 1 & 5 \\
5 & S. epidermidis & 1 & 2 & 3 \\
6 & E. coli & 30 & 22 & 52 \\
7 & K. oxytoca & 6 & 6 & 12 \\
8 & Proteus mirabilis & 2 & 3 & 5 \\
9 & Acinetobacter baumannii & 0 & 5 & 5 \\
10 & Enterobacter aerogenes & 3 & 2 & 5 \\
11 & Citrobacter freundii & 3 & 2 & 5 \\
12 & Neisseria spp & 3 & 2 & 5 \\
13 & Pseudomonas aeruginosa & 1 & 1 & 2 \\
& Total & 115 & 116 & 231 \\
\hline
\end{tabular}

\begin{tabular}{|c|c|c|c|c|}
\hline S. No. & Antibiotics & $\begin{array}{c}\text { Total } \\
\text { isolates } \\
\text { tested }\end{array}$ & $\begin{array}{l}\text { Resistant } \\
\text { isolates }\end{array}$ & $\begin{array}{l}\text { Percentage } \\
\text { of resistance } \\
\text { isolates }\end{array}$ \\
\hline 1 & Amoxycillin & 140 & 42 & 30.00 \\
\hline 2 & Cephalexin & 140 & 43 & 30.71 \\
\hline 3 & Cefoxitin & 140 & 29 & 20.71 \\
\hline 4 & Cefixime & 140 & 14 & 10.00 \\
\hline 5 & Cefotaxime & 140 & 17 & 12.14 \\
\hline 6 & Ceftriaxone & 140 & 14 & 10.00 \\
\hline 7 & Co-trimoxazole & 140 & 11 & 7.85 \\
\hline 8 & Erythromycin & 140 & 21 & 15.00 \\
\hline 9 & Gentamycin & 140 & 14 & 10.00 \\
\hline 10 & Ciprofloxacin & 140 & 22 & 15.71 \\
\hline 11 & Ofloxacin & 140 & 26 & 18.57 \\
\hline 12 & Norfloxacin & 140 & 23 & 16.42 \\
\hline 13 & Cloxacillin & 140 & 18 & 12.86 \\
\hline 14 & Imipenem & 140 & 7 & 5.00 \\
\hline
\end{tabular}

Samples from 79 non-alcoholic volunteers showed 117 isolates whereas 87 Alcoholic volunteers' samples showed 114 isolates. However, the difference was statistically insignificant $(\mathrm{p}$ value $=0.9480) . S$. anreus is the most predominant isolates in both alcoholic and non-alcoholic volunteers.

The diversity of Skin microbiome was found some higher in Smokers with respect to Non-Smokers, though statistically the data was insignificant ( $p$ value $=0.9858$ ). $S$. aureus is the most predominant isolates in both Smokers and non-smokers.

\section{ANTIBIOTIC SUSCEPTIBILITY PATTERN OF THE ISOLATES}

Antibiotic susceptibility pattern of Gram positive isolates Out of 14 common antibiotics tested against Gram positive isolates, Imipenem was the most sensitive antibiotic with sensitivity of $95.00 \%$ (133 out of 140 isolates), followed by Cefixime and Ceftriaxone and Gentamycin with equal sensitivity of $90.00 \%$ (126 out of 140 isolates). Likewise, the least sensitive antibiotic includes Cephalexin with resistivity of $30.71 \%$ (43 out of 140) isolates, followed by Amoxycillin which exhibited resistivity of $30 \% 42$ out of 140 isolates. Detail information has been exhibited in Table 4.

Antibiotic susceptibility pattern of $S$. aureus

Out of 14 common antibiotics used against the most abundant skin bacterial normal flora, S. aureus, Imipenem and Co-trimoxazole were the most susceptible antibiotic with susceptibility of $91.46 \%$ (75 out of 82 isolates), followed by Ceftriaxone and Gentamycin with equal susceptibility of $86.58 \%$ (71 out of 82 isolates). Likewise, the least susceptible antibiotic includes Amoxycillin with resistivity of $31.71 \%$ (26 out of 82 isolates), followed by Cefotoxin which exhibited resistivity of $29.27 \%$ (24 out of 82 isolates).

Antibiotic susceptibility pattern of Gram negative isolates

Out of 14 common antibiotics used against Gram negative isolates, Amikacin was the most susceptible antibiotic with susceptibility of $100 \%$ (91 out of 91 isolates), followed by Nitrofuratoin and and Imipenem with equal susceptibility of $98.90 \%$ (90 out of 91 isolates). Likewise, the least susceptible antibiotic includes Amoxycillin with resistivity of $28.57 \%$ (26 out of 91 isolates), followed by Cefixime, Co-trimoxazole and Norfloxacin which exhibited resistivity of $18.68 \%$ (17 out of 91 isolates).

\section{Antibiotic susceptibility pattern of E. coli}

Out of 14 common antibiotics used against the most abundant Gram negative isolates, E. coli, Amikacin was the most susceptible antibiotic with susceptibility of $100 \%$ (52 out of 52 isolates), followed by Nitrofuratoin, Chloramphenicol and and Imipenem with equal susceptibility of $98.07 \%$ (51 out of 52 isolates). Likewise, the least susceptible antibiotic includes Amoxycillin with resistivity of $32.69 \%$ (17 out of 52 isolates), followed by Co-trimoxazole which exhibited resistivity of $23.07 \%$ (12 out of 52 isolates).

\section{DISCUSSION}

Skin bacterial isolates have been found to be higher in Kathmandu with respect to Bharatpur and Lukla, which we conclude is due to altitude related factors. Skin bacteria significantly grew more comfortably in mild altitude rather than extreme ones. Kathmandu lies in the altitude of $1400 \mathrm{~m}$ (4600 feet), whereas Bharatpur and Lukla which lie at altitude of 208 meter (682 feet) and $2860 \mathrm{~m}$ (9380 feet) respectively above sea level. The barometric pressure, temperature, along with other several factors affects the growth of skin microbiome that grows in margin between the natural environment and human body. 
The lowest skin microbiome isolates have been observed in Lukla, the highest altitude among three sites of the study. Zeng et $a 1^{14}$ also found the similar result. They found the people at high altitude Tibet plateau (3750-3861 m above sea level) had significantly less diverse skin microbiomes than at low altitude Sichuan basin area (319-1421 m above sea level).

Xing and $\mathrm{Hahn}^{18}$ observed the similar result that the diversity of Bacterioplankton in four high-altitude Tibetan freshwater lakes was only one-fifth of the Bacterioplankton diversity in seven low-altitudes.

Several factors may influence bacterial diversity at high altitude; for example, the higher UVR intensity at high altitude may reduce bacterial community diversity. Other environmental factors such as temperature and oxygen concentration may also contribute to the altitude associated differences in skin microbiome diversity and structure; however, these factors are all correlated and it is difficult to explain their individual roles in shaping the skin microbiome. ${ }^{14}$

It is important to characterize the skin bacterial flora in mammals living at high altitude to determine whether the skin microbiome has adapted to the extreme environment and whether such adaptations aid in resistance to the development of skin diseases caused by extreme conditions such as UVR.

Eighty-six female samples exhibited 116 isolates whereas 80 male samples exhibited 115 isolates. This shows slightly higher ratio of isolates in male, though the difference is too small to be significant. The slight lower number of isolates in female may be due to application of some skin cosmetics that are antibacterial. Ying and Zeng et al, ${ }^{19}$ however, concluded that hormone metabolism, perspiration rate and skin surface $\mathrm{pH}$, can also account for gender wise differences of bacterial flora.

No significant relationship has been observed between the skin bacteria with smoking habit in our study though the isolates were slightly higher in smokers. Less study has been done to co-relate the skin microbiome with smoking habit. However, studies have been done for gut microbiome relating to smoking habits. Lee and Yun et al $(2018)^{20}$ observed significant difference of gut microbiome between never and current smokers. They found that current smokers had an increased proportion of the phylum Bacteroidetes with decreased Firmicutes and Proteobacteria compared with never smokers, whereas there were no differences between former and never smokers.

Biederman and Mwinyi et al (2013) ${ }^{21}$ observed profound shifts in the gut microbial composition after smoking cessation with an increase of Firmicutes and Actinobacteria and a lower proportion of Bacteroidetes and Proteobacteria on the phylum level. In addition, after smoking cessation, there was an increase in microbial diversity.

Biedermann and Brulisauer et al (2014) $)^{22}$ found that intestinal microbiota composition in humans is influenced by smoking. They concluded characteristics of observed microbial shifts suggest a potential mechanistic association to alterations in body weight subsequent to smoking cessation.

Eighty-seven alcoholic volunteers exhibited 114 isolates, whereas 79 non-alcoholic volunteers exhibited 117 isolates. This indicates the higher abundance of skin microbiome in non-alcoholic individuals than alcoholic one, though the relationship is not significant. Research has not been focused to relate skin Microbiome with alcohol drinking habits. Andrew and Frederico et al $(2014)^{23}$ found significant decrease in oral microbiomes in alcohol drinkers than in alcohol non-drinkers. There has been shift of microbial diversity on alcohol consumption.

Out of 14 common antibiotics used against Gram positive isolates, Imipenem was the most susceptible antibiotic with susceptibility of $95.00 \%(133 / 140)$, and Cephalexin was the most resistant with resistivity of $30.71 \%(43 / 140)$. The result was similar to the most predominant Gram positive skin flora, $S$. aureus. Similarly, out of 14 common antibiotics used against Gram negative isolates, Amikacin was the most susceptible antibiotic with susceptibility of $100 \%$ (91/91), and Amoxycillin was the least effective antibiotic with resistivity of $28.57 \%(26 / 91)$. The result was similar to the most predominant Gram negative skin flora, E. coli. Similar finding for the sensitivity and resistivity was reported by Shrestha D. et al. ${ }^{24} 2016$ and Oteo et al.(2001). ${ }^{25}$

\section{CONCLUSION}

The result indicates skin bacterial flora varies along the altitude the host human resides. These results lay the groundwork for further studies exploring the possibility of high-altitude adaptation of beneficial skin-associated microbial communities in humans.

\section{Limitations}

The research is based on plate culture technique and limited for only aerobic microorganism growing on NA, MA, BA and CA.

\section{ACKNOWLEDGEMENTS}

We acknowledge Kantipur General Hospital, Kathmandu, Pasang Lhamu Memorial Hospital, Lukla and Balkumari College, Chitwan, for providing their laboratory for sample collection, and processing. We would like to acknowledge University Grant Commission, Nepal for funding the research. 
Hearty acknowledgement goes to Dr. Megh Raj Banjara, Head, Central Department of Microbiology, Tribhuvan University, Kathmandu, Dr. Dev Raj Joshi, Central Department of Microbiology, Tribhuvan University, Kathmandu, and Dr. Shardulendra Prasad Sherchand, Department of Global Environmental Health Sciences, Tulane University, United States for continuous inspiration and support in manuscript writing.

\section{REFERENCES}

1. Elizabeth A Grice and Julia A. The skin microbiome, Nature Review Microbiology 2011; 9(4): 244-253.

2. Chiller K, Selkin BA and Murakawa GJ. Skin microflora and bacterial infections of the skin. Journal of Investigative Dermatology Symposium Proceedings2001; 6(3):170-174.

3. Yu Y, Dunaway S, Champer J, Kim J and Alikhan A. Changing our microbiome: Probiotics in dermatology. The British Journal of Dermatology 2019; doi: 10.1111/bjd.18088. Review. PubMed PMID: 31049923

4. Legato MJ. Worlds within worlds: the human microbiome. Gender Medicine 2011; 8(5):339-341.

5. Flandroy L, Poutahidis T, Berg G, Clarke G, Dao MC, Decaestecker E, et al. The impact of human activities and lifestyles on the interlinked microbiota and health of humans and of ecosystems. Science of the Total Environment 2018; 627:1018-1038.

6. O'Sullivan JN, Rea MC, O'Connor PM, Hill C and Ross RP. Human skin microbiota is a rich source of bacteriocin-producing staphylococci that kill human pathogens. FEMS Microbiology Ecology 2019; 95(2):241.

7. McBride ME, Duncan WC and Knox JM. The environment and the microbial ecology of human skin. Applied and environmental microbiology 1977; 33(3): 603-608.

8. Tagami H. Location-related differences in structure and function of the stratum corneum with special emphasis on those of the facial skin. International Journal of Cosmetic Science 2008;30(6):413-434.

9. Fierer N, Hamady M, Lauber CL and Knight R. The influence of sex, handedness, and washing on the diversity of hand surface bacteria. Proceedings of National Academy of Sciences of the United States of America 2008; 105 (46): 17994-17999.

10. Staudinger T, Pipal A and Redl B. Molecular analysis of the prevalent microbiota of human male and female forehead skin compared to forearm skin and the influence of make-up. Journal of Applied Microbiology 2011; 110: 1381-1389.

11. Kueneman JG, Parfrey LW, Woodhams DC, Archer HM, Knight R and McKenzie VJ. The amphibian skin-associated microbiome across species, space and life history stages. Molecular Ecology 2014; 23: 1238-1250.
12. Costello EK, Lauber CL, Hamady M, Fierer N, Gordon JI and Knight R. Bacterial community variation in human body habitats across space and time. Science 2009; 326(5960):1694-1697.

13. Jablonski NG and Chaplin G. Human skin pigmentation as an adaptation to UV radiation. Proceedings of National Academy of Sciences 2010; U.S.A. 107 (Supplementary 2): 8962-8968.

14. Zeng B, Zhao J, Guo W, Zhang S, Hua Y, Tang J, et al. HighAltitude Living Shapes the Skin Microbiome in Humans and Pigs. Frontier Microbiology 2017; 8: Article:1929, Page: 1-10.

15. Capone KA, Dowd SE, Stamatas GN and Nikolovski J. Diversity of the human skin microbiome early in life, The Journal of Investigative Dermatology 2011; 131(10): 2026-2032.

16. Krieg NR, Bergey's Manual of Systematic Bacteriology - 1984, Vol 1, Williams and Wilkins.

17. Sneath PHA, Bergey's Manual of Systematic Bacteriology - 1986. Vol 2, Williams and Wilkins.

18. Xing $\mathrm{P}$, Hahn $\mathrm{MW}$ and $\mathrm{Wu} \mathrm{QL}$. Low taxon richness of bacterioplankton in high-altitude lakes of the eastern tibetan plateau, with a predominance of Bacteroidetes and Synechococcus spp. Applied and Environmental Microbiology 2009; 75(22):7017-7025.

19. Ying S, Zeng DN, Chi L, Tan Y, Galzote C, Cardona C, et al. The Influence of Age and Gender on Skin-Associated Microbial Communities in Urban and Rural Human Populations. PLoS One 2015; 10 (10):e0141842.

20. Lee SH, Yun Y, Kim SJ, Lee EJ, Chang Y, Ryu S, et al. Association between Cigarette Smoking Status and Composition of Gut Microbiota: Population-Based Cross-Sectional Study. Journal of Clinical Medicine 2018; 7(9):282.

21. Biedermann L, Zeitz J, Mwinyi J, Sutter-Minder E, Rehman A, Ott SJ, et al. Smoking cessation induces profound changes in the composition of the intestinal microbiota in humans. PLoS One 2013; 8(3):e59260.

22. Biedermann L, Brülisauer K, Zeitz J, Frei P, Scharl M, Vavricka SR, et al. Smoking cessation alters intestinal microbiota: insights from quantitative investigations on human fecal samples using FISH. Inflammatory Bowel Diseases 2014; 20(9):1496-1501.

23. Thomas AM, Gleber-Netto FO, Fernandes GR, Amorim M, Barbosa LF, Noronha Francisco AL, et al, Alcohol and tobacco consumption affects bacterial richness in oral cavity mucosa biofilms, BMC Microbiology 2014; 14(250):1-12.

24. Shrestha D, Sherchand S, Gurung K, Manandhar S, Shrestha B and Sherchan S. Prevalence of Multidrug Resistant ExtendedSpectrum ß-Lactamase-Producing Bacteria from Different Clinical Specimens in Kathmandu Model Hospital, Kathmandu, Nepal. EC Microbiology 2016; 4: 676.

25. Oteo J, Campos $\mathrm{J}$, Baquero $\mathrm{F}$ and Spanish members of European Antimicrobial Resistance Surveillance System. Escherichia coli in 27 Spanish hospitals participating in the European Antimicrobial Resistance Surveillance System. Journal of Antimicrobial Chemotherapy 2001; 42:16-18.

\footnotetext{
Authors Contribution:

DS- Concept of the study, setting research methodology, managing logistics, sample collection, processing and analyzing the result and writing the manuscript: RS- Sample collection, processing and Interpretation of results; RSH, LBS and DRB- Concept of the study, setting research methodology.

Work attributed to:

Central Department of Microbiology, Tribhuvan University, Kritipur, Kathmandu, Nepal.

Orcid ID:

Dipendra Shrestha - (D https://orcid.org/0000-0002-8855-1389

Raju Shrestha - (1) https://orcid.org/0000-0001-6918-0757

Dr. Rene S. Hendriksen - (1) https://orcid.org/0000-0003-2934-8214

Dr. Luna B. Sharma - (1) https://orcid.org/0000-0001-7491-2115

Dr. Dwij R. Bhatta - (D https://orcid.org/0000-0002-9845-3838

Source of Support: This piece of research work has been funded by University Grant Commission, Bhaktapur, Nepal. Conflict of Interest: The authors share no conflict of interest in research article submitted.
} 